\title{
Performance of the Boditech iCHROMA Covid-19 IgG antibody assay with the external quality control for UK NIBSC (National Institute of Biological Standards and Control)
}

J Bolodeoku ${ }^{1 *}$, M Bass $^{1}$, TK Kim ${ }^{2}$, C Anyaeche ${ }^{3}$ and V Retnasingham ${ }^{1}$

${ }^{1}$ PathDirect Laboratory, New Malden, Surrey. KT3 3TX, UK.

${ }^{2}$ Boditech Med Inc, Korea.

${ }^{3}$ Pathaway Services Limited, Headlands House, 1 King Court, Kettering Parkway, Kettering, NN15 6WJ. UK.

*Corresponding Author: J Bolodeoku, JB Consulting MDP Limited, 1 Bell Street, Maidenhead, SL6 1 BU, UK.

Received date: October 27, 2020; Accepted date: November 11, 2020; Published date: November 16,2020

Citation: Bolodeoku J., Bass M., TK Kim, Anyaeche C., and Retnasingham V., (2020) Performance of the Boditech iCHROMA Covid-19 IgG antibody assay with the external quality control from UK NIBSC (National Institute of Biological Standards and Control) J, Clin Med Rev and Rep. 2(8); DOI:10.31579/2690-8794/048

Copyright: (02020, J Bolodeoku, This is an open access article distributed under the Creative Commons Attribution License, which permits unrestricted use, distribution, and reproduction in any medium, provided the original work is properly cited.

\section{Abstract}

Background: There is a need for laboratories to participate in EQA schemes to achieve a harmonization of test results and to improve serological testing and research on COVID-19 and SARS-CoV-2. The Boditech iCHROMA point of care immunoassay analyser has a Covid-19 antibody assay for the qualitative determination of $\operatorname{IgG}$ antibodies in human whole blood/serum/plasma. The National Institute for Biological Standards and Control (NIBSC) in the United Kingdom has a portfolio of reference and research reagents, including reagents for EQA that are available to laboratories to help them set up and develop accurate diagnostic tests for SARS-CoV-2 assays.

Objectives: To determine the performance of the Boditech iCHROMA Covid-19 IgG antibody assay using the external quality control material provided by the UK NIBSC (National Institute for Biological Standards and Control).

Results: The Boditech iCHROMA Covid-19 IgG assay using the cut off index $>1.1$, reported the results of the 33 positive control samples as positive with index range from $19.50-29.00$, with a mean of 23.75 and standard deviation of $\mathrm{SD}$ of 2.53. It also reported the results of the 33 negative control samples as negative with an index range of 0.00 for all samples.

Conclusion: The performance of the Boditech iCHROMA Covid-19 IgG antibody assay using external quality control material from the UK NIBSC was very good, confirming the precision of the Boditech iCHROMA Covid 19 IgG antibody method.

Keywords: NIBSC; iCHROMA; COVID 19; IgG antibody; EQA

\section{Introduction}

The detection of SARS-CoV-2 infection is important in the understanding of this infection and the importance of the EQA in harmonizing the various methods of detecting the antibodies is appropriate. Antibodies against SARS-CoV-2 indicate previous exposure to the virus. Accurate and rapid diagnostic testing of antibodies against SARS-CoV-2 will be paramount in the understanding and controlling the spread of the coronavirus disease. There are a number of assays developed world-wide. In optimizing the performance of these assays it is important to ensure that these method results are validated by external sources. External quality assurance (EQA) involves the analysis of samples with unknown values from an external source providing objective evidence of the laboratory and method competence. EQA is a part of clinical governance and helps precision of the respective assay or method and satisfies regulatory guidelines [1]. The first EQA of antibody diagnostic testing for SARS-CoV-2 was carried out in 2004, $45 \%$ of the laboratories detected anti-SARS antibodies correctly in serum samples [2], More recently, a pilot EQA scheme was conducted by an accredited international EQA provider on laboratories with methods for detecting anti-SARS-CoV-2 specific antibodies (IgG, $\operatorname{IgA}$ and $\operatorname{IgM}$ ), the overall success rate for the anti-SARS-CoV-2 IgG, IgA, and IgM tests was $80 \%, 72.7 \%$, and $16.7 \%$, respectively [3]. These results highlighted the need for laboratories to participate in EQA schemes to achieve a harmonization of test results and to improve serological testing and research on COVID-19 and SARSCoV-2. The importance of harmonization is crucial and a number of organizations such as the WHO and its collaborators for maintaining internal standards (IS) like the Paul Ehrlich Institute, the Food and Drug Administrations (FDA), Center for Biologics, Evaluation and Research (CDER) and National Institute for Biological Standards and Control (NIBSC) have an ongoing program to develop an IS to harmonize the measurement of SARS-CoV-2 [4]. The National Institute for Biological Standards and Control (NIBSC) in the United Kingdom has a portfolio of reference and research reagents, including reagents for EQA that are available to laboratories to help them set up and develop accurate diagnostic tests for SARS-CoV-2 assays [5]. We have recently shown a 
very good correlation between the Boditech iCHROMA IgG antibody assay and Abbott Architect SARS-CoV-2 IgG antibody assay. Both methods are used to detect the immunoglobulin class IgG antibodies to the nucleocapsid protein of SARS-CoV-2 [6]. In this study, we evaluated the performance of the Boditech iCHROMA Covid $19 \mathrm{IgG}$ antibody assay using the NIBSC control.

\section{Materials \& Methods}

Positive Control: External Quality Control reagent for anti-SARS-CoV2 antibody (NIBSC code: 20/B764-01

Material: Antibody, human, convalescent plasma, CE-marked.

Intended use: Diagnostics laboratories Quality Control reagent.

Description: External Quality Control to monitor the assay performance, equipment and operators on a run to run or day to day basis. CE marked under ISO 13485. Fulfils the requirements of a reference material as described in ISO 15189.

Negative Control: External Quality Control reagent for anti-SARS-CoV2 antibody (NIBSC code: 20/B737-02).

Material: Antibody, human, convalescent plasma, CE-marked.

Intended use: Diagnostics laboratories Quality Control reagent.

Description: External Quality Control to monitor the assay performance, equipment and operators on a run to run or day to day basis. CE marked under ISO 13485. Fulfils the requirements of a reference material as described in ISO 15189.

Boditech iCHROMA Method: The test uses a sandwich immunodetection method; fluorescence labelled conjugates in a dried detection buffer binds to antibody in sample, forming antibody-antigen complexes, and migrates onto nitrocellulose matrix to be captured by the other immobilized anti-human IgG on test strip. The more antigenantibody complexes lead to stronger fluorescence signal by the detector antigen which is processed by iCHROMA. The iCHROMA processes the signal using a cut off index of $0.9-1.1$, results $<0.9$ are interpreted as negative, results between 0.9 and 1.1 are interpreted as indeterminate and results $>1.1$ are interpreted as positive.

The positive and negative controls from NIBSC were run every day that a Covid 19 antibody assay was performed between 07/07/2020 and 20/08/2020 using the iCHROMA IgG assay described below:

1. Transfer $150 \mu \mathrm{L}$ of detector diluent using a pipette into the detector tube containing a granule. When the granule is completely dissolved it becomes the detection buffer.

2. Aspirate $10 \mu \mathrm{L}$ of whole blood/serum/plasma/control with a pipette, and add into the detector tube, close and shake the tube at least 10 times.

3. Pipette out $75 \mu \mathrm{L}$ of the content of the tube and load it into the sample well on the test cartridge and leave for 10 minutes.

4. Insert the test cartridge into the cartridge holder in ICHROMA II device and press start

5. Read the result on the display screen of the iCHROMA II device.

\section{Results}

The Boditech iCHROMA Covid-19 IgG assay using the cut off index $>1.1$, reported the results of the 31 positive control samples as positive with an index range from $19.50-29.00$, with a mean of 23.75 and standard deviation (SD) of 2.53, see table 1 and figure 1 .

\begin{tabular}{|c|c|c|}
\hline Day & Result & IgG Index result \\
\hline $07-07-20$ & Positive & 22.80 \\
\hline $08-07-20$ & Positive & 28.80 \\
\hline 09-07-20 & Positive & 25.00 \\
\hline $10-07-20$ & Positive & 28.00 \\
\hline $13-07-20$ & Positive & 22.70 \\
\hline $14-07-20$ & Positive & 20.90 \\
\hline $15-07-20$ & Positive & 22.30 \\
\hline $16-07-20$ & Positive & 24.90 \\
\hline $17-07-20$ & Positive & 29.00 \\
\hline $20-07-20$ & Positive & 28.20 \\
\hline $21-07-20$ & Positive & 21.80 \\
\hline $22-07-20$ & Positive & 19.10 \\
\hline $23-07-20$ & Positive & 26.00 \\
\hline $27-07-20$ & Positive & 24.60 \\
\hline $28-07-20$ & Positive & 25.50 \\
\hline 29-07-20 & Positive & 19.50 \\
\hline $30-07-20$ & Positive & 19.90 \\
\hline $31-07-20$ & Positive & 21.60 \\
\hline 03-08-20 & Positive & 23.50 \\
\hline 04-08-20 & Positive & 22.60 \\
\hline 05-08-20 & Positive & 25.20 \\
\hline $06-08-20$ & Positive & 23.10 \\
\hline 07-08-20 & Positive & 22.90 \\
\hline $10-08-20$ & Positive & 24.40 \\
\hline $11-08-20$ & Positive & 23.70 \\
\hline $12-08-20$ & Positive & 23.60 \\
\hline $13-08-20$ & Positive & 22.30 \\
\hline $17-08-20$ & Positive & 25.00 \\
\hline $18-08-20$ & Positive & 24.40 \\
\hline $19-08-20$ & Positive & 23.40 \\
\hline $20-08-20$ & Positive & 21.40 \\
\hline
\end{tabular}

Table 1. Showing the positive control IgG result and its respective index result 


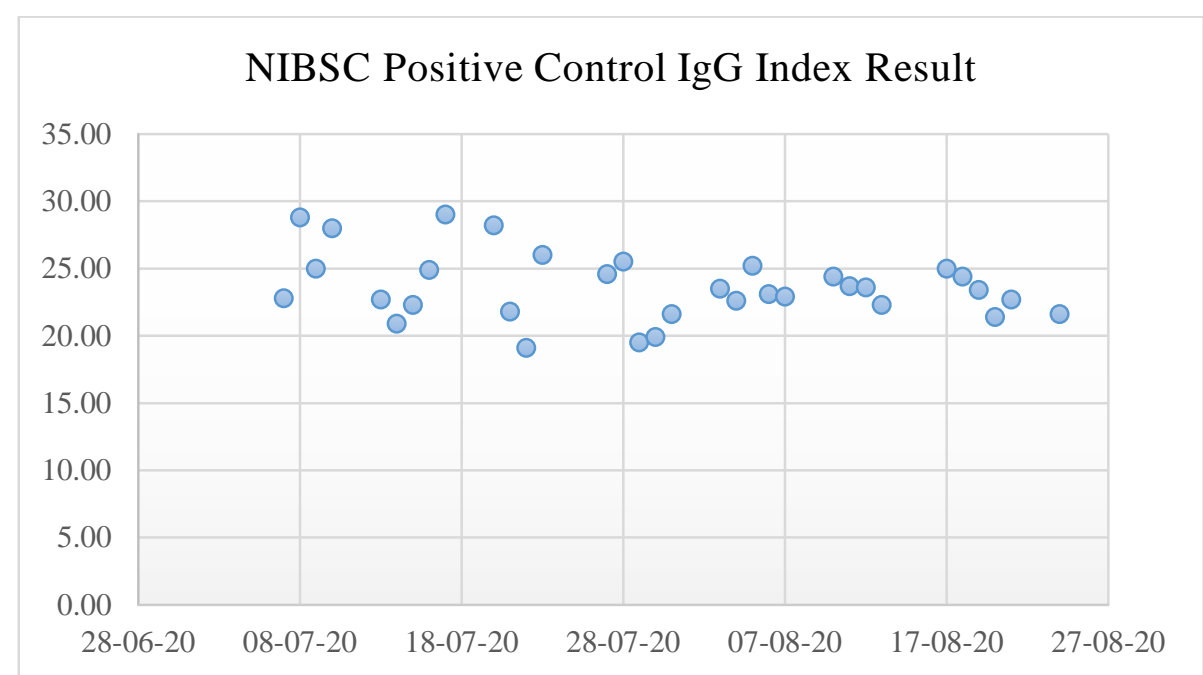

Figure 1. Showing the positive control $\mathrm{IgG}$ result and its respective index result

The Boditech iCHROMA Covid-19 IgG assay using the cut off index $>1.1$, reported the results of the 33 negative control samples as negative with an index range of 0.00 for all samples. See table 2.

\begin{tabular}{|c|c|c|}
\hline Day & Result & IgG Index result \\
\hline $07-07-20$ & Negative & 0.00 \\
\hline $08-07-20$ & Negative & 0.00 \\
\hline $09-07-20$ & Negative & 0.00 \\
\hline $10-07-20$ & Negative & 0.00 \\
\hline $13-07-20$ & Negative & 0.00 \\
\hline $14-07-20$ & Negative & 0.00 \\
\hline $15-07-20$ & Negative & 0.00 \\
\hline $16-07-20$ & Negative & 0.00 \\
\hline $17-07-20$ & Negative & 0.00 \\
\hline $20-07-20$ & Negative & 0.00 \\
\hline $21-07-20$ & Negative & 0.00 \\
\hline $22-07-20$ & Negative & 0.00 \\
\hline $23-07-20$ & Negative & 0.00 \\
\hline $27-07-20$ & Negative & 0.00 \\
\hline $28-07-20$ & Negative & 0.00 \\
\hline $29-07-20$ & Negative & 0.00 \\
\hline $30-07-20$ & Negative & 0.00 \\
\hline $31-07-20$ & Negative & 0.00 \\
\hline $03-08-20$ & Negative & 0.00 \\
\hline $04-08-20$ & Negative & 0.00 \\
\hline $05-08-20$ & Negative & 0.00 \\
\hline $06-08-20$ & Negative & 0.00 \\
\hline $07-08-20$ & Negative & 0.00 \\
\hline $10-08-20$ & Negative & 0.00 \\
\hline $11-08-20$ & Negative & 0.00 \\
\hline $12-08-20$ & Negative & 0.00 \\
\hline $13-08-20$ & Negative & 0.00 \\
\hline $17-08-20$ & Negative & 0.00 \\
\hline $18-08-20$ & Negative & 0.00 \\
\hline $19-08-20$ & Negative & 0.00 \\
\hline $20-08-20$ & Negative & 0.00 \\
\hline
\end{tabular}

Table 2. Showing the negative control IgG result and its respective index result

\section{Discussion}

The performance of the Boditech iCHROMA with EQA materials from organizations such as the United Kingdom National External Quality Assessment Service (UKNEQAS) and Randox International Quality Assessment Scheme (RIQAS) has been well described with analytes such as human chorionic gonadotrophin (HCG) [7], follicle stimulating hormone (FSH) [7], leutinising hormone (LH) [7], Vitamin D [8], Prostate Specific Antigen (PSA) [9], testosterone [10], ferritin [11]. The detection of SARS-CoV-2 infection is important in the understanding of this infection and the importance of the EQA in harmonizing the various methods of detecting the antibodies is appropriate. The preparedness and implementation of EQA have been instrumental in the rapid expansion of Covid 19 testing capacity in countries like Korea [12]. In a recent pilot EQA scheme for anti-SARS-CoV-2 antibody testing laboratories, 16 laboratories using commercially available test systems were invited into the scheme and provided samples. Fourteen (14) out of the 16 laboratories $(87.4 \%)$ submitted their data. All 14/14 (100\%) of the laboratories submitted data on IgG, 10/14 (71.4\%) on IgA and 5/14 (35.7\%) on IgM. The results of the laboratories testing SARS-CoV-2 IgG had a success rate of $80 \%$ in identifying the control samples and their results were robust with regards to concordance rate and accuracy [3].

The laboratory uses internal control which comprises of pooled samples of Covid 19 positive patients when running samples using the iCHROMA anti-SARS-CoV-2 IgG assay, in this study, using the external quality control from NIBSC, the iCHROMA anti-SARS-CoV-2 IgG assay identified 33/33 (100\%) times the positive control sample, as positive, with an index range from $19.50-29.00$, with a mean of 23.75 and standard deviation of SD of 2.53. Whilst the Boditech iCHROMA antiSARS-CoV-2 IgG assay identified 33/33 (100\%) times the negative control sample, as negative, with a consistent index range of 00.00. The range of the index estimated in the NIBSC positive control sample was $19.50-29.00$, interestingly the index range observed in patient samples was between 22.8 and 74.6, indicating that the NIBSC positive control was within the range of the lower levels seen in clinical samples [6].

In conclusion, we have previously shown that the Boditech iCHROMA Covid-19 IgG antibody assay has close agreement with Abbott Architect SARS-CoV-2 IgG antibody assay and now the performance of the Boditech iCHROMA Covid-19 IgG antibody assay using EQA material from the UK NIBSC was very good, this study confirms the precision of the Boditech iCHROMA Covid $19 \mathrm{IgG}$ antibody method from material issued by an external EQA provider. 


\section{Reference}

1. Sciacovelli L, Sechchiero S, Zardo L, Plebani M. (2010) The role of external quality assessment. Biochemia Medica; 20 (2) : 160 164

2. Niedrig M, Leitmeyer K, Lim W, Peiris M, Mackenzie JS, Zambon M. (2005) First external quality assurance of antibody diagnostic for SARS new coronavirus. J Clin Vir; 34 (1): 22 - 25.

3. Haselmann V, Özçürümez MK, Klawonn F, Ast V, Gerhards C, Eichner R, Costina V, Dobler G, Geilenkeuser WJ, Wölfel R, Neumaier M. (2020) Results of the first pilot external quality assessment (EQA) scheme for anti-SARS-CoV2-antibody testing. Clin Chem Lab Med.

4. Page, M., Almond, N., Rose, N.J. et al. (2020) Diagnostics and the coronavirus: don't let the standards slip. Nat Biotechnol 38, 673-674.

5. New reagent available to support global diagnostic testing of coronavirus (COVID 19). Press release.

6. Bass M, Bolodeoku J, Stevenson E, Anyaeche C, Kim TK, Retnasingham V. (2020) Agreement of the Point of Care (POCT) Boditech iCHROMA ${ }^{\mathrm{TM}}$ Covid 19 IgG antibody assay with the Abbott Architect SARS-CoV-2 IgG antibody assay. Ann Immunol Immunother, 2 (2) : 000121

7. Bolodeoku J, Bains S, Pinkney S, Coker O, Fakokunde A. (2017) Comparison of the Point of Care Test (POCT), i-CHROMA ${ }^{\mathrm{TM}}$ Human Chorionic Gonadotrophin (HCG), Leutinizing Hormone (LH) and Follicle Stimulating Hormone (FSH) methods in serum with the other methods in the Randox International Quality
Assessment Scheme (RIQAS). Clin Obstet Gynecol Reprod Med 3 (4) : 1-7

8. Bolodeoku J, Pinkney S, Bains S, Andrade ML. (2018) An assessment of automated Vitamin D measurement methods including a Point of Care Testing method, i-CHROMA ${ }^{\mathrm{TM}}$ using the Randox International Quality Assurance Scheme (RIQAS) Biomed J Sci \& Tech Res 3 (4)

9. Bolodeoku J, Coker O, Bains S, Anyaeche C, Kim K, Chinegwundoh F. (2018) The performance of the point of care test (POCT) i-CHROMA PSA method using internal and external quality assessment schemes: United Kingdom External Quality Assessment Service (UKNEQAS) and Randox International Quality Assessment Service (RIQAS). Curr Trends Med Diagn Meth: CTMDM-104.

10. Bolodeoku J, Coker O, Bains S, Anyaeche C, Kim K, Chinegwundoh F. (2019) The accuracy performance of the Point of Care Test (POCT) Boditech i-CHROMA testosterone method using external quality assessment schemes: RIQAS and UKNEQAS. Am J Biomed Sci \& Res. 4 (6).

11. Bolodeoku J, Coker O, Bains S, Kim KT, Anyaeche C (2020) An evaluation of the performance of the point of care test (POCT) iCHROMA ferritin method in the Randox International Quality Assessment Service (RIQAS). J Biochem Analyt Stud 4 (1).

12. Heungsup S, Cheon-Kwon Y, Myung-Guk H, Sang-Won L, Hyukmin L, Sail C, Wee Gyo L, Won-Ki M. (2020) Preparedness and Rapid Implementation of External Quality Assessment Helped Quickly Increase COVID-19 Testing Capacity in the Republic of Korea, Clinical Chemistry, Volume 66, Issue 7, Pages 979-981.
This work is licensed under Creative Commons Attribution 4.0 License

To Submit Your Article Click Here: Submit Manuscript

DOI: $10.31579 / 2690-8794 / 048$
Ready to submit your research? Choose Auctores and benefit from:

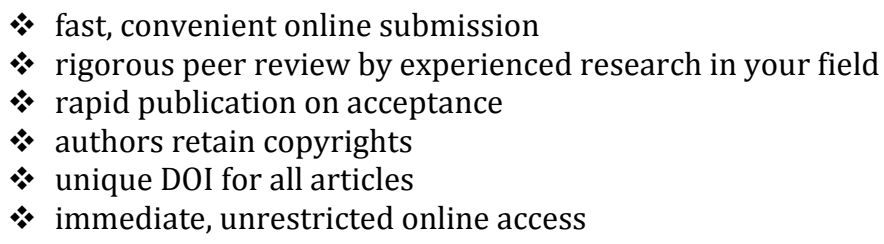

At Auctores, research is always in progress.

Learn more www.auctoresonline.org/journals/clinical-medical-reviewsand-reports 